\title{
Carbon Dot-based Fluorescent Antibody Nanoprobes as Brain Tumour Glioblastoma Diagnostics
}

\author{
Mattia Ghirardello, ${ }^{1}$ Radhe Shyam, ${ }^{1}$ Xia Liu, ${ }^{2}$ Teodoro Garcia-Millan, ${ }^{1}$ Imke Sittel, ${ }^{1}$ F. Javier \\ Ramos-Soriano, ${ }^{1}$ Kathreena Kurian ${ }^{2, *}$ and M. Carmen Galan ${ }^{1, *}$ \\ ${ }^{1}$ School of Chemistry, University of Bristol, Bristol, United Kingdom; ${ }^{2}$ Bristol Medical \\ School, Public Health Sciences, Southmead Hospital, University of Bristol, Bristol, United \\ Kingdom \\ E-mail: kathreena.kurian@bristol.ac.uk and m.c.galan@bristol.ac.uk
}

\begin{abstract}
The development of efficient and sensitive tools for the detection of brain cancer in patients is of the utmost importance particularly because many of these tumours go undiagnosed until the disease has advanced and when treatment is less effective. Current strategies employ antibodies (Abs) to detect Glial Fibrillary Acid Protein (GFAP) in tissue samples, since GFAP is unique to the brain and not present in normal peripheral blood, and it relies on fluorescent reporters.

Herein we describe a low cost, practical and general method for the labelling of proteins and antibodies with fluorescent carbon dots (CD) to generate diagnostic probes that are robust, photostable and applicable to the clinical setting. The two-step protocol relies on the conjugation of a dibenzocyclooctyne (DBCO)-functionalised $C D$ with azide functionalised proteins by combining amide conjugation and strain promoted alkyne-azide cycloaddition (SPAAC) ligation chemistry. The new class of $A b-C D$ conjugates developed using this strategy was successfully used for the immunohistochemical staining of human brain tissues of patients with glioblastoma (GBM) validating the approach. Overall, these novel fluorescent probes offer a promising and versatile strategy in terms of costs, photostability and applicability which can be extended to other Abs and protein systems.
\end{abstract}

\section{Introduction}

Overall less than $20 \%$ of brain tumour patients are alive 5 years after diagnosis, in part because they present late with large inoperable tumours. ${ }^{[1]}$ There is an urgent need to develop new sensitive tests of brain tumours to help general practitioners in primary care. ${ }^{[2]}$ The most common malignant primary brain tumour called glioblastoma is characterised by abnormal blood vessels resulting in a leaky Blood Brain Barrier (BBB). ${ }^{[3]}$ Glial Fibrillary Acid Protein (GFAP) is unique to the brain and not present in normal peripheral blood. Antibodies targeting GFAP are used to diagnose gliomas in tissue samples. There is evidence that GFAP crosses the leaky BBB and is an early non-specific peripheral blood biomarker which predates the clinical diagnosis of glioblastoma. ${ }^{[4]}$ However, GFAP levels are too low for routine detection by commonly used protein diagnostic tests such as ELISA, and more sensitive methods for its identification are needed..$^{[5]}$

Fluorescent labelling of proteins is a common strategy to investigate their role and function in cells, tissues and organisms. ${ }^{[6]}$ Traditional efforts rely on the use of molecular dyes, which are usually expensive and predisposed to photobleaching. Alternatively, fluorescent nanoparticles can be tuned to exhibit high stability, sensitivity and specificity for their desired target without the limitations of organic fluorophores and as a result these nanoprobes have found many applications as more robust tools in the areas of bioimaging, drug delivery and diagnostics. ${ }^{[7]}$

Among the different types of luminescent nanomaterials, carbon dots have emerged as a new class of carbon-based fluorescent nanomaterials with semi-spherical morphology, unique optical and physico-chemical properties such as chemical inertness, high water solubility, resistance to photobleaching, low cost of fabrication, and very low cytotoxicity ${ }^{[8]}$ These carbon based fluorescent 
nanomaterials have been hailed as alternative probes to semiconductor quantum dots which have been linked to heavy metal toxicity which restricted their use in vivo applications. ${ }^{[9]}$ As a results, the use of carbon-based nanomaterials in biology as a platform for gene delivery, ${ }^{[10]}$ cell imaging, ${ }^{[11]}$ diagnosis, ${ }^{[12]}$ and as theranostics ${ }^{[13]}$ has raised a lot of interest.

CDs can be easily produced via the thermal degradation of readily available substances such as citric acid and ethylenediamine furnishing CDs with high fluorescent quantum yield. The fluorescent excitation and emission pattern of CDs can be tuned by changing the synthetic conditions, variables such as the kind of solvent, temperature and the ratio of precursors used during the preparation may provide different nanoparticles able to emit in different spectral regions. ${ }^{[8 b]}$ Therefore, the combination of these features makes of CDs excellent candidates for their use as fluorophores for Abs labelling. However, despite the great advantages offered by CDs for many biosensing applications, ${ }^{[14]}$ their use as fluorophores for Abs labelling is still underdeveloped and Ab conjugation strategies to CDs have not been fully developed for direct clinical applications. ${ }^{[15]}$

To this extent, we envisioned the use of fluorescent carbon dots (CDs) for the development of cheap and photostable probes for Abs functionalization that can be used for the detection of GFAP in clinical samples.

Herein, we describe the development of a practical, low cost and general strategy for the labelling of Abs with fluorescent CDs. This first generation of $A b-C D$ conjugates combines EDC and strain promoted alkyne-azide cycloaddition (SPAAC) ligation chemistry to generate a new class of Ab-CD conjugates which are robust and photostable (Figure 1). Moreover, the clinical versatility of the novel Ab-probes is demonstrated in the immunohistochemical staining of human brain tissues of patients with glioblastoma GBM.

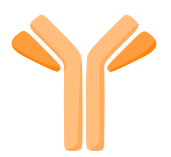

$\mathrm{Ab}$

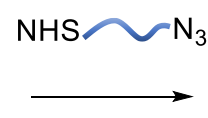

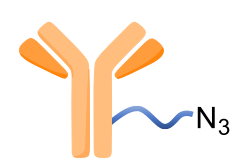

$\mathrm{Ab}-\mathrm{N}_{3}$

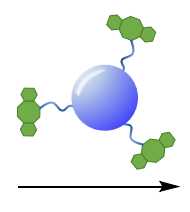

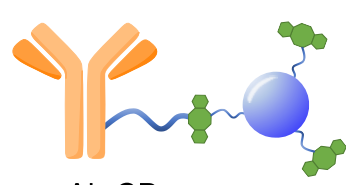

$\mathrm{Ab}-\mathrm{CD}$<smiles>N#CCCNC(=O)CCC(=O)ON1C(=O)CCC1=O</smiles>

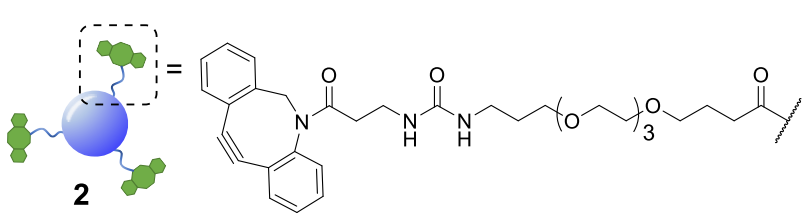

Figure 1. General Ab-CD conjugation strategy.

\section{Results and Discussion}

\subsection{Synthesis of dibenzocyclooctyne (DBCO)-functionalised fluorescent carbon dots}

The synthesis of dibenzocyclooctyne (DBCO)-functionalised CD 2 ready to be conjugated to azidodecorated Abs started from acid functionalised $C D$ 3, which were prepared in one pot from citric acid and ethylenediamine under microwave irradiation (domestic microwave oven, $300 \mathrm{~W}$ ) following a modified procedure by Mondal et al. ${ }^{[16]}$ (Figure 2A). The reaction mixture was dissolved in distilled $\mathrm{H}_{2} \mathrm{O}$ and precipitated in an excess of acetone several times to give acid-functionalized CDs, which after dialysis and centrifugal filtration ( $10 \mathrm{kDa}$ molecular weight cut-off membrane) afforded monodisperse blue emitting nanoparticles as evidenced by fluorescence measurements (Figure 2B). TEM revealed the presence of quasi-spherical nanoparticles with an average size between $2-5 \mathrm{~nm}(\mathrm{~N}=262)$ and a lattice interspacing of $0.34 \mathrm{~nm}$ (Figure $2 \mathrm{C}$ ) which correlate to a graphite core structure. ${ }^{[17]}$ 
A)

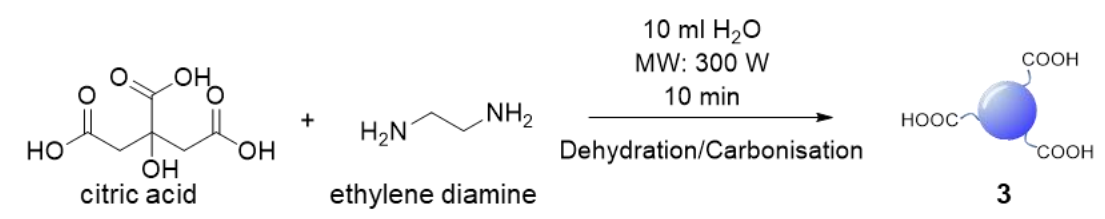

B)

C)
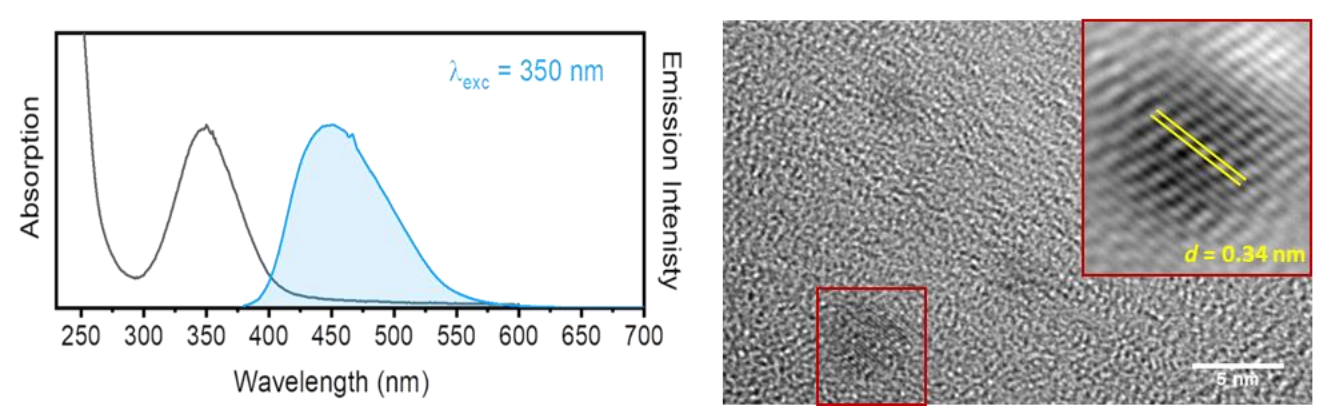

Figure 2. A) Synthetic approach for the synthesis of acidic coated CDs 3. B) Absorption and emission spectra of CD 3. C) TEM image of CD 3. Lattice interspacing $(d)$ for single dots is included.

Functionalization of CD 3 with DBCO-linker 9, which was prepared in 4 steps and $47 \%$ overall yield, afforded DBCO-CDs 2 (Scheme 1). In brief, mono-amine protection of commercially available 4,7,10trioxa-1,13-tridecanediamine 4 with $\mathrm{Boc}_{2} \mathrm{O}$ in $\mathrm{CH}_{2} \mathrm{Cl}_{2}$ gave $\mathbf{5}^{[18]}$ in $99 \%$ yield. The free amine in $\mathbf{5}$ was then reacted with 4-nitrophenyl chloroformate to form activated carbamate 6 , which could then be treated with commercial DBCO-amine $\mathbf{7}$ to give $\mathbf{8}$ in 55\% yield over the 2 steps. Boc deprotection in the presence of TFA/ $\mathrm{CH}_{2} \mathrm{Cl}_{2}$ afforded 9 ready for $\mathrm{CD}$ conjugation. HATU mediated nanoparticle functionalization of acid coated CD 3 with 9 was carried out using a 1:0.5 w/w ratio of 3:9, which was found to be optimum to ensure the nanoparticles remained in solution despite the hydrophobic coating. Furthermore, ${ }^{1} \mathrm{H}, \mathrm{HSQC}$ and Diffusion Ordered (DOSY) NMR spectroscopy analysis demonstrated the successful conjugation of DBCO moieties on the CD (See ESI Figures S11-13).

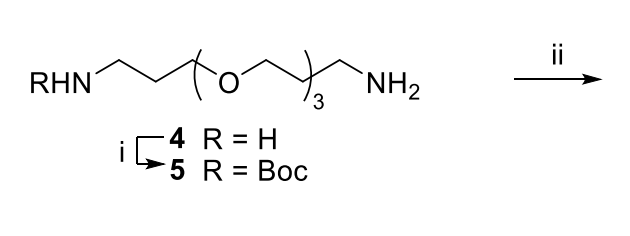<smiles>CC(C)(C)OCCCCOCCCNC(=O)Oc1ccc([N+](=O)[O-])cc1</smiles>

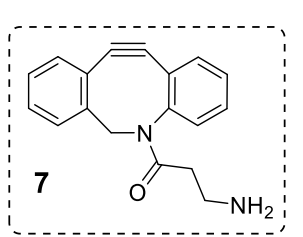

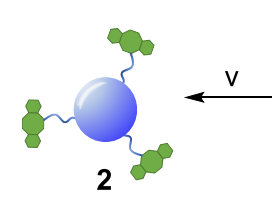<smiles>[R9]NCCC(C)OCCSCCNC(=O)NCCC(=O)N1Cc2ccccc2C#Cc2ccccc21</smiles>

Scheme 1. Reagents and conditions: i) $\mathrm{Boc}_{2} \mathrm{O}, \mathrm{DCM}, 4 \mathrm{~h}, 0^{\circ} \mathrm{C}$ to rt, 99\%; ii) 4-nitrophenyl chloroformate, Py, DCM, 3 h, $0{ }^{\circ} \mathrm{C}$ to rt, 87\%; iii) 7, Py, DIPEA, DMF, 63\%; iv) TFA, DCM, 1.5 h, rt, 86\%; v) 3, HATU, DIPEA, DMF, $5 \mathrm{~h}$, rt.

\subsection{Protein Conjugation Strategy}

There are several antibody-drug conjugation strategies available which include: amide formation, periodate oxidation of carbohydrates in the Fc region and subsequent functionalization of the novel aldehyde function produced within the glycosidic moiety, click reactions involving 1,3-dipolar cycloadditions, thiol maleimide conjugations and thiol-mediated alkylation among others. ${ }^{[19]}$ Among those, the EDC/NHS-promoted amide formation by targeting primary amines found on lysine residues, appears to be one of the most common and direct approaches for nanoparticle loading. ${ }^{[14,20]}$ Control 
over the $A b /$ nanoparticle loading ratio to avoid the over functionalization of the $A b$, as well as the type and length of spacer molecule between the probe and Ab are essential to avoid loss of protein's pharmacokinetic properties. Moreover, excessive labelling may also interfere with the antigen-biding event. In this context, an Ab/drug ratio of around 1:4 is found to be optimal[ ${ }^{[21]}$ and this parameter was considered in the preparation of our Ab-CD conjugates. NHS activated conjugation represents the golden standard as it allows for a fast and reliable Abs covalent functionalization, NHS-functionalised molecules react with solvent exposed primary amines such as lysine residues on the surface of the Abs. ${ }^{[22]}$ Taking into account the above considerations, NHS-linker $\mathbf{1}$ (for its preparation see ESI section $3.3)^{[23]}$ featuring an azido motif that can selectively react with the DBCO-CD 2. Moreover, both 1 and 2 were designed with a triethylene glycol spacer to help with water solubility and to reduce steric hindrance between the $A b$ and the surface of the $C D$.

\subsubsection{BSA-CD conjugation strategy}

With both CD-DBCO 2 and NHS-linker 1 in hand, the feasibility of our labelling approach was initially evaluated on bovine serum albumin (BSA) protein, as an inexpensive model system (Figure 2A). In the first step, the protein was functionalised with the azido-containing linker 1 , in brief a solution of BSA in PBS $(100 \mu \mathrm{L}, 36.1 \mu \mathrm{M})$ was reacted with excess amounts of $\mathbf{1}$ (Figure $2 \mathrm{~A}$, different molar excess of 1 were tested, entries a-f: from 40 to 1333 eq.) under gentle shaking at room temperature for $4 \mathrm{~h}$. Removal of the excess of 1 and washes via spin filtration over $30 \mathrm{KDa}$ cut-off membrane gave 10a-f with different degrees of functionalization from approximately 6 to a maximum of 32 linker units per protein as determined by Matrix Assisted Laser Desorption/Ionization (MALDI) mass spectrometry using the spotting procedure described by Signor et al. ${ }^{[24]}$ (See figure 2A, and ESI: figure S20 and Table S1).

Once the protein is decorated with the azido functionalities, chemoselective Cu-free click conjugation with DBCO-CD 2 was attempted in PBS by mixing 10a (BSA with $6 \mathrm{~N}_{3}$-linker units) and 2 at room temperature for $16 \mathrm{~h}$. A 5-fold excess of $\mathbf{2}$ in weight with respect to the protein was used to ensure all the available $\mathrm{N}_{3}$ moieties were conjugated. Following spin filtration ( $30 \mathrm{KDa}$ cut-off membrane) to remove the excess of $\mathbf{2}, \mathrm{BSA}-\mathrm{CD}$ conjugate $\mathbf{1 1}$ a was obtained as determined by MALDI (Figure 2B). The conjugation of CDs to BSA caused a shift toward larger molecular weights and a broadening of the peak as expected from protein conjugation with a disperse nanoparticle system such as our CDs. ${ }^{[25]}$

Gel electrophoresis was also used to further confirm the effective BSA-CDs conjugation, by allowing us to compare the MW of the different protein adducts (Figure $2 \mathrm{C}$ ). Whereas the addition of 6 low molecular weight (MW) $\mathrm{N}_{3}$-linkers on 10a did not show any significant changes on the gel when compared to with native BSA (Figure $2 \mathrm{C}$, i vs ii), a noticeable increase in MW was shown for the BSA$\mathrm{CD}$ adduct 11a (Figure $2 \mathrm{C}$, i vs iii), which further validates the MALDI data. Gel electrophoresis analysis of BSA-N $\mathrm{N}_{3}$ derivatives $\mathbf{1 0 b}-\mathrm{f}$ was also possible (see ESI figure S22).

Moreover, to exclude the possibility of non-specific BSA adsorption on CD nanoparticles, unfunctionalized BSA, which lacks azido motifs, and DBCO-CDs were pre-mixed together and run on the same well showing no MW changes with respect to BSA alone (Figure $2 \mathrm{C}$, i vs iv) which demonstrated the chemospecific labelling of the protein via SPAAC reaction. 
A)

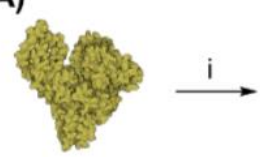

BSA

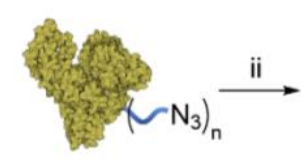

10a-f

B)

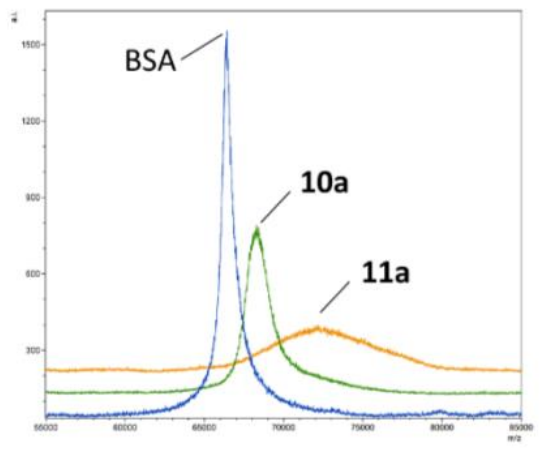

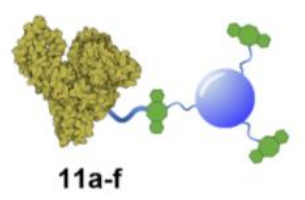

$\mathrm{a} \approx 6 \quad \mathrm{~d} n \approx 27$

b $n \approx 10$ e $n \approx 29$

c $n \approx 22$ f $n \approx 32$

C)

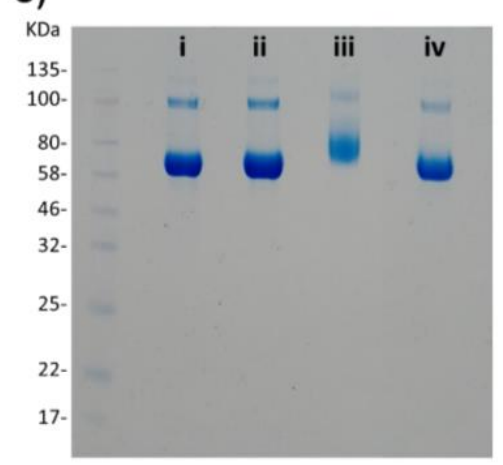

Figure 2. A) Reagents and conditions: i) 1, PBS, 4 h, rt; ii) 2, 16 h, rt. B) MALDI spectra of BSA, 15a, and 16a. Intensity is expressed as arbitrary units (a.i.). C) NuPAGE Gel electrophoresis of BSA derivatives: i) native BSA, ii) 10a, iii) 11a, and iv) native BSA (no $\mathrm{N}_{3}$ present) mixed with 2.

\subsubsection{Anti-GFAP Abs-CD conjugation}

Having demonstrated successful protein labelling with our strategy, CD conjugation on clinically relevant rabbit polyclonal anti-glial fibrillary acidic protein antibodies (anti-GFAP Abs) was next attempted. NHS-linker 1 conjugation to anti-GFAP Abs was performed as before (Figure $3 \mathrm{~A}$ ). A solution of Abs in PBS (11.1 $\mu \mathrm{M})$ was treated with an excess of 1 (Figure $3 \mathrm{~A}$, entries a-d: $0.12-2.41 \mu \mathrm{mol}$ ) and left shaking at room temperature over $4 \mathrm{~h}$. MALDI analysis of the products showed peak broadening and shifts towards higher MWs for the azido functionalised anti GFAP Abs which could be used to estimate the average degree of substitution (Figure 3B, and ESI: Figure S24 and Table S2). In general, it was found that a maximum of 30 azido containing linkers could be conjugated to the Abs at the higher concentrations, while a degree of functionalization of 4 linker moieties was achieved when 100 molar equivalents of 1 was used for the conjugation, which is optimum to maintaining Ab function and good pharmacokinetic and toxicology profile. ${ }^{[21]}$ The anti-GFAP Abs- $\mathrm{N}_{3}$ derivatives $12 \mathrm{a}$-d were then treated with an excess of DBCO-CD 2 as previously described for BSA and following spin filtration over $50 \mathrm{KDa}$ cut-off membrane to remove the excess of unconjugated 2, and anti-GFAP Abs-CD conjugates 13a-d were generated. Gel electrophoresis was used to confirm CD labelling of the anti GFAP-Abs. As for the BSA model gel electrophoresis showed negligible differences in terms of MW for 12a-d when compared to native Abs (Figure S25 i vs iii-vi). It is worth noting that although MALDI clearly shows MS differences between native and azido functionalised Abs, no changes on MW were detectable on the gels for neither anti-GFAP Abs or anti-GFAP Abs- $\mathrm{N}_{3}$ since the molecular weight differences between the species is negligible at the level of MW resolution for gel electrophoresis. Indeed, the different Abs-CD probes showed significant increase in MW for 13a-d, which correlated to their degree of azido functionalization, when compared to native anti-GFAP Abs (Figure $3 C$ ). ${ }^{[26]}$ To confirm that the $C D$ labelling of the $A b s$ is not due to non-specific interactions, fluorescence images of a native $A b s$ and $A b s-N_{3}$ that were treated with DBCO-CD 2 prior to purification showed fluorescent labelling only for azido containing Abs as expected (Figure 3D). Moreover, as previously demonstrated for BSA, gel electrophoresis of unfunctionalized Abs were pre-mixed with $\mathbf{2}$ and run on the same well showed no MW changes with respect to Abs alone (Figure S25, i vs ii) confirming the absence of nonspecific interactions between the $C D$ and the Abs. 
Furthermore, western blot analysis using human GFAP with 13a (functionalised with 4 linker units) was used to demonstrate the novel anti-GFAP Ab-CD 13a adducts retained their ability to recognise the target antigen. To that end, a goat anti-rabbit secondary antibody equipped with a near IR probe was used on the western blot, confirming the presence of the rabbit anti-GFAP Abs bound to the human GFAP antigen (Figure 5E). ${ }^{[27]}$

A)

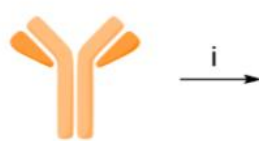

Abs

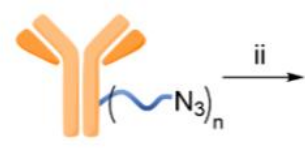

12a-d

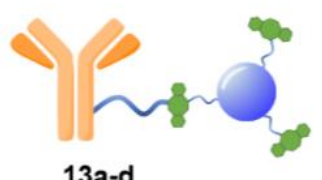

$13 a-d$

$$
\begin{aligned}
& \text { a } n \approx 4 \\
& \text { b } n \approx 9 \\
& \text { c } n \approx 26 \\
& \text { d } n \approx 30
\end{aligned}
$$

B)

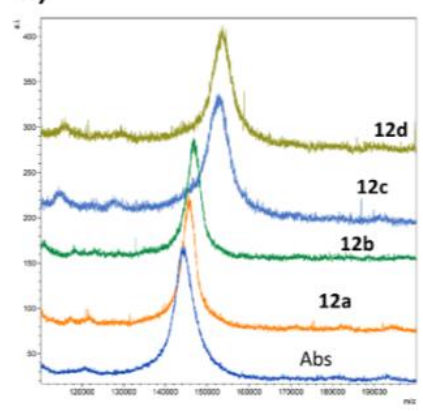

C)

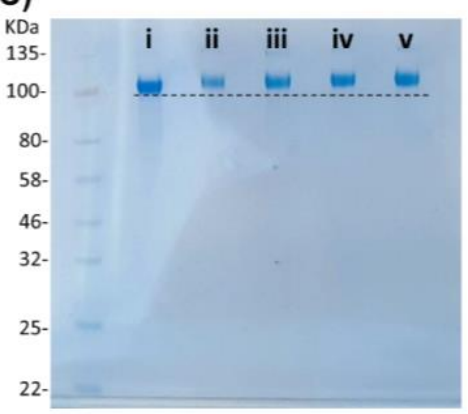

D)

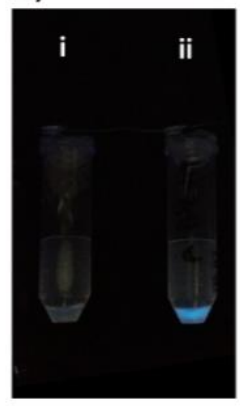

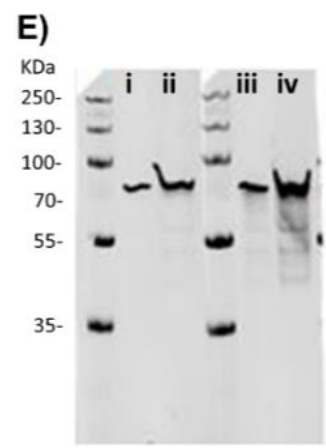

Figure 3. A) Reagents and conditions: i) 1, PBS, $4 \mathrm{~h}, \mathrm{rt}$; ii) 2, $16 \mathrm{~h}, \mathrm{rt}$. B) MALDI spectra of Abs, and azide derivatives 17a-d, Intensity is expressed as arbitrary units (a.i.). C) NuPAGE Gel electrophoresis of Abs derivatives: i) native Abs, ii) 13a, iii) 13b, iv) 13c and v) 13d. D) Comparison under the UV light of the fluorescent emission of i) nonfunctionalise Abs mixed with 2 and purified, and ii) purified 13a. E) Western blot using recombinant human GFAP protein and 13a, i) $20 \mathrm{ng}$ of GFAP and 13a 1:1000 dilutions, ii) $100 \mathrm{ng}$ of GFAP and 13a 1:1000 dilutions, iii) $20 \mathrm{ng}$ of GFAP and unlabelled Abs, iv) $100 \mathrm{ng}$ of GFAP and unlabelled Abs, IRDye 680RD goat anti-rabbit IgG was used as secondary antibody.

\subsection{Anti-GFAP Abs-CD Immunostaining of Clinical Tissue Brain Cancer Patient Samples}

GFAP immunostaining is the most commonly used method to examine the distribution of astrocytes and the hypertrophy of astrocytes in response to neural degeneration or injury as in the development of glioblastoma. ${ }^{[4]}$ To demonstrate the versatility of our CD-based Ab labels for diagnosis applications, we have examined GFAP in 13 formalin-fixed paraffin embedded biopsy brain tumour samples from different patients (12 glioblastoma, IDH wildtype, WHO Grade 4 and 1 negative control schwannoma, WHO Grade I, see ESI: table S3) using our conjugated antibody 13a (Figure 4). We identified immunofluorescence within all the glioblastoma cases (as assessed by a consultant neuropathologist KMK) using the conjugated anti-GFAP antibody 13a (Figure $4 \mathrm{~A}$ and $4 \mathrm{~B}$, for the complete set of pictures see ESI Figure S27). We identified the correct pattern of cytoplasmic staining (blue) of the GFAP intermediate filament in the glioblastoma cell cytoplasm (Figure 4A and 4B). The intensity and extent of GFAP immunopositivity showed inter and intra-tumoural heterogeneity in keeping with known biological variation between cases. The negative control schwannoma showed no positive staining using the conjugated GFAP antibody as expected (Figure 4C). There was no variation of GFAP staining with age, sex or molecular parameters within the small cohort as expected. In addition, control labelling experiments of glioblastoma samples with CD-DBCO 2 without the Abs, showed no labelling further demonstrating that Abs-CD 13a is responsible for the labelling observed (see ESI, Figure S26A). 


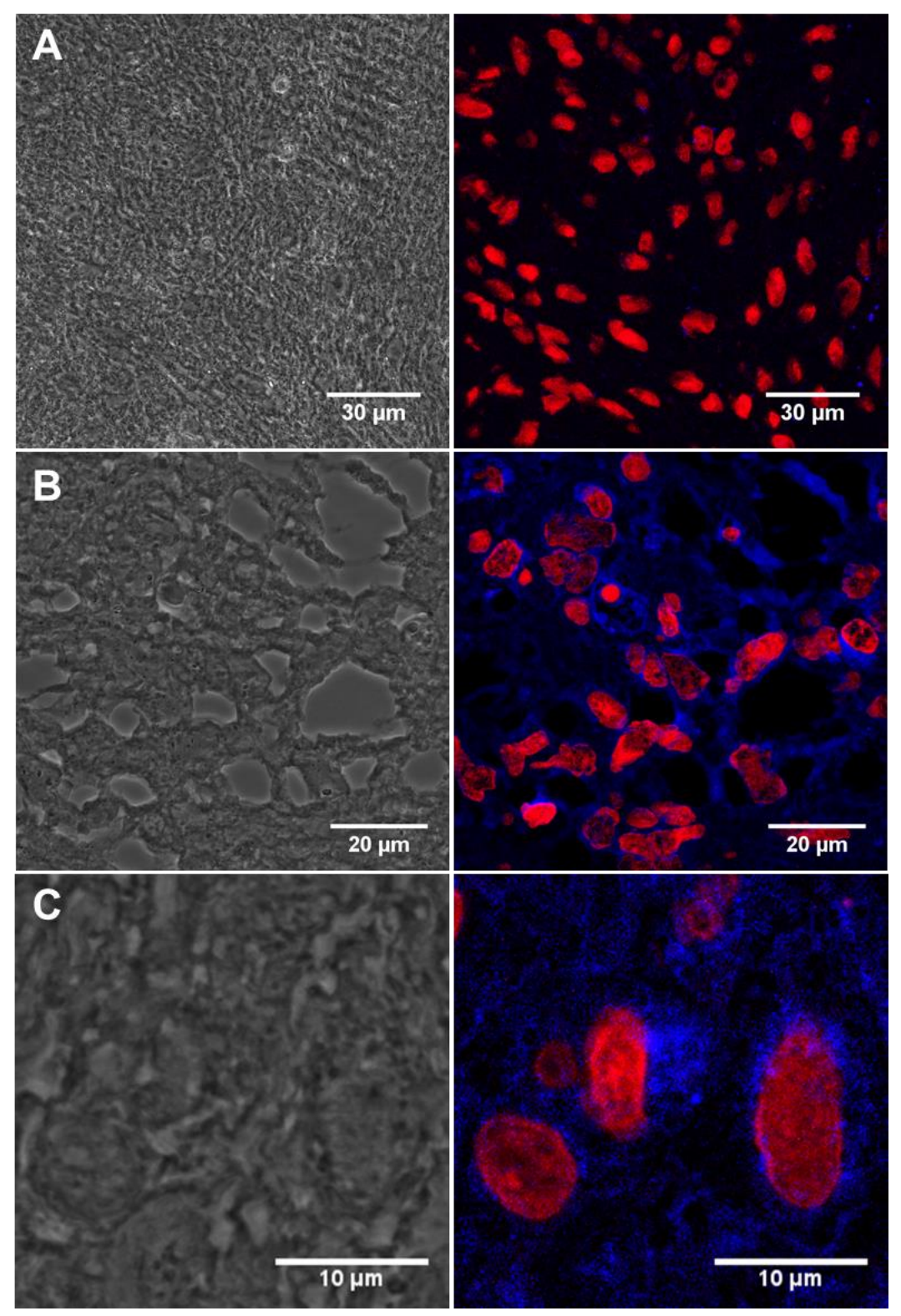

Figure 4. A) Confocal image of the negative control benign schwannoma stained with Anti-GFAP Abs-CD 13a showing immunofluorescence red labelling nuclei and negative for blue GFAP staining (patient ID: N1214A1). B) Immunostained tissue section of malignant brain tumour glioblastoma stained with 13a showing immunofluorescence red labelling nuclei and blue labelling cobweb pattern of intermediate filament GFAP (patient ID: 08/0160b). Magnified view of 13a labelled tissue section of malignant brain tumour glioblastoma showing blue immunopositivity in a single cell (patient id: 10/0053). Left panel = bright field showing monolayer. Right panel = Anti-GAFP Abs-CD probe 13a labelled tissue. For full scale pictures of $A B$ and $C$ refer to ESI, Figure S27 $A, K$ and $G$ respectively.

\section{Conclusions}

In summary, we have successfully developed a new class of carbon dot-based fluorescence labels that can be "clicked" onto suitably functionalised proteins such as Abs in a chemoselective manner. The two-step strategy relies on the used DBCO-functionalised CDs and alkyne-functionalised proteins that can be easily prepared by simple amide conjugation methods from suitably functionalised linkers with control over degree of functionalization. The novel anti-GFAP Abs-CD probes developed here retained their ability to interact with the human GFAP. Moreover, we have demonstrated our novel probes show reliable binding in a range of clinical malignant brain tumour glioblastoma cases, in tissue 
sections. Overall, this new class of probes offer a promising and versatile strategy in terms of costs, photostability and applicability which can be extended to other Abs and protein systems. This type of cheap and rapid nanoparticle test have the potential to pave the way for novel strategies to identify the presence of tumour markers such as GFAP in clinical samples to support early diagnosis of brain tumours in primary care. Early diagnosis would potentially improve survival and reduce anxiety in these patients by giving them more surgical and treatment options earlier in the course of their disease.

\section{Materials and methods}

\subsection{General Experimental}

Reagents and solvents were purchased as reagent grade from Sigma Aldrich or ThermoFisher and used without further purification. For column chromatography, silica gel 60 (230-400 mesh, 0.040-0.063 $\mathrm{mm}$ ) was purchased from Merck and for gel filtration Sephadex G-25 from GE Healthcare. Thin Layer Chromatography (TLC) was performed on aluminium sheets coated with silica gel 60 F254 purchased from Merck. Dialysis was performed with Cole-Parmer Spectra Por Dialysis Tubing, 500-1000 MWCO. Centrifugal spin filtration was performed on Amicon Ultra- $0.5 \mathrm{~mL}$ purchased from Merck. Carbon dots were prepared using a domestic microwave oven $(300 \mathrm{~W})$. NMR spectra were recorded on Bruker AV $400 \mathrm{MHz}$ or AV $500 \mathrm{MHz}$ spectrometers, using the residual solvent peaks as internal reference at 298 $\mathrm{K}$. Chemical shifts are reported as parts per million and coupling constants (J) given in Hertz. All the assignments were confirmed by one- and two-dimensional NMR experiments (DEPT, COSY, HSQC). Mass spectra were obtained by the University of Bristol mass spectrometry service using electrospray ionisation (ESI) acquired on a Micromass LCT mass spectrometer or aVG Quattro mass spectrometer and MALDI spectra were acquired on Bruker ultrafleXtreme 2 (TOF). Zeta potential analysis was carried out using Malvern Instruments Nano-Z ZEN 2600 and conducted in distilled $\mathrm{H}_{2} \mathrm{O}$ at a concentration of $4 \mathrm{mg} \cdot \mathrm{mL}^{-1}$. BSA was purchased from ThermoFisher (23209). Polyclonal Rabbit AntiGlial Fibrillary Acidic Protein was purchased from Agilent Dako (Z033401-2). Recombinant Human GFAP protein, used in the Western Blot test was purchased from abcam (ab114149). Secondary IRDye ${ }^{\circledR}$ 680RD Goat anti-Rabbit IgG used in the Western Blot test were purchased by LI-COR. Human brain tissue samples were kindly provided by the Southmead Hospital, (University of Bristol, UK).

\subsection{Chemical synthesis}

Compound 6: To a stirred solution of 4-nitrophenyl chloroformate $(2.98 \mathrm{~g}, 14.79 \mathrm{mmol})$ and Py $(1 \mathrm{~mL}$, $12.33 \mathrm{mmol})$ in anhydrous $\mathrm{DCM}(70 \mathrm{~mL})$ at $0{ }^{\circ} \mathrm{C}$, a solution of $5(1.58 \mathrm{~g}, 4.93 \mathrm{mmol})$ in dry DCM (20 $\mathrm{mL}$ ), was added over $1 \mathrm{~h}$ at $0{ }^{\circ} \mathrm{C}$. Once the addition was completed, the solution was stirred for further $2 \mathrm{~h}$ at room temperature. The reaction was quenched by the addition of saturated aq. $\mathrm{NH}_{4} \mathrm{Cl}$ solution $(50 \mathrm{~mL})$ and the mixture was extracted with DCM $(3 \times 50 \mathrm{~mL})$. The combined organic phases were dried with anhydrous $\mathrm{MgSO}_{4}$, filtered and concentrated under reduced pressure. The residue was purified by column chromatography on silica gel (Hex/EtOAc 1:0 to 3:7, v/v) furnishing 6 ( $2.08 \mathrm{~g}, 87 \%$ yield) as a transparent syrup. ${ }^{1} \mathrm{H}$ NMR $(500 \mathrm{MHz}$, Chloroform-d) $\delta 8.27-8.20(\mathrm{~m}, 2 \mathrm{H}, \mathrm{Ar}), 7.35-7.27(\mathrm{~m}, 2 \mathrm{H}$, $\operatorname{Ar}), 6.12(\mathrm{~s}, 1 \mathrm{H}, \mathrm{NH}), 4.89(\mathrm{~s}, 1 \mathrm{H}, \mathrm{NH}), 3.69-3.62\left(\mathrm{~m}, 8 \mathrm{H}, \mathrm{OCH}_{2}\right), 3.59\left(\mathrm{dd}, J=5.8,3.5 \mathrm{~Hz}, 2 \mathrm{H}, \mathrm{OCH}_{2}\right)$, $3.51\left(\mathrm{t}, J=6.0 \mathrm{~Hz}, 2 \mathrm{H}, \mathrm{OCH}_{2}\right), 3.42\left(\mathrm{q}, J=6.0 \mathrm{~Hz}, 2 \mathrm{H}, \mathrm{NCH}_{2}\right), 3.21$ (q, $\left.J=6.5 \mathrm{~Hz}, 2 \mathrm{H}, \mathrm{NCH}_{2}\right), 1.87(\mathrm{~h}, J=$ $\left.6.0 \mathrm{~Hz}, 2 \mathrm{H}, \mathrm{CH}_{2} \mathrm{CH}_{2} \mathrm{CH}_{2}\right), 1.77-1.69\left(\mathrm{~m}, 2 \mathrm{H}, \mathrm{CH}_{2} \mathrm{CH}_{2} \mathrm{CH}_{2}\right), 1.43$ (s, 9H, $\left.\mathrm{CH}_{3}\right) .{ }^{13} \mathrm{C} \mathrm{NMR}\left(126 \mathrm{MHz}, \mathrm{CDCl}_{3}\right)$ ठ 156.3, 156.2, 153.4, 144.8, 125.2, 122.1, 79.2, 70.7, 70.7, 70.4, 70.3, 70.1, 69.7, 40.2, 38.6, 29.8, 29.1, 28.6. HRMS (ESI) $\mathrm{m} / \mathrm{z}$ : Calcd for $\mathrm{C}_{22} \mathrm{H}_{35} \mathrm{~N}_{3} \mathrm{O}_{9} \mathrm{Na}(\mathrm{M}+\mathrm{Na})^{+} 508.2265$, found 508.2279

Compound 8: To a stirred solution of $6(81 \mathrm{mg}, 0.29 \mathrm{mmol})$ and Py $(0.5 \mathrm{~mL}, 6.21 \mathrm{mmol})$ in anhydrous DCM (5 mL), a solution of DBCO-amine $7(286 \mathrm{mg}, 0.59 \mathrm{mmol})$ in anhydrous DCM $(2 \mathrm{~mL})$ was added dropwise at room temperature, followed by the addition of DIPEA (153 $\mu \mathrm{L}, 0.88 \mathrm{mmol})$ at room temperature. The solution was stirred for $4 \mathrm{~h}$ at room temperature, then diluted with $\mathrm{DCM}(100 \mathrm{~mL})$, 
washed wit saturated aq. $\mathrm{NH}_{4} \mathrm{Cl}$ solution $(2 \times 50 \mathrm{~mL})$ and brine $(1 \times 50 \mathrm{~mL})$. The organic phase was dried with anhydrous $\mathrm{MgSO}_{4}$, filtered, and concentrated under reduced pressure. The residue was purified by column chromatography on silica gel (EtOAc/MeOH 1:0 to 9:1, v/v) furnishing 8 (116 mg, $63 \%$ yield) as a transparent oil. ${ }^{1} \mathrm{H}$ NMR $(500 \mathrm{MHz}$, Chloroform- $d) \delta 7.66(\mathrm{~d}, J=7.6 \mathrm{~Hz}, 1 \mathrm{H}, \mathrm{Ar}), 7.42-$ $7.23(\mathrm{~m}, 7 \mathrm{H}, \mathrm{Ar}), 5.12\left(\mathrm{~d}, J=13.9 \mathrm{~Hz}, 1 \mathrm{H}, \mathrm{CH}_{2 \mathrm{a}}{ }^{\mathrm{DBCO}}\right), 5.05(\mathrm{~s}, 1 \mathrm{H}, \mathrm{NH}), 5.00(\mathrm{~d}, J=6.3 \mathrm{~Hz}, 1 \mathrm{H}, \mathrm{NH}), 4.86$ $(\mathrm{s}, 1 \mathrm{H}, \mathrm{NH}), 3.69-3.47\left(\mathrm{~m}, 13 \mathrm{H}, \mathrm{CH}_{2 \mathrm{~b}}{ }^{\mathrm{DBCO}}, \mathrm{OCH}_{2}\right), 3.30-3.10\left(\mathrm{~m}, 6 \mathrm{H}, \mathrm{NCH}_{2}\right), 2.56-2.48\left(\mathrm{~m}, 1 \mathrm{H}, \mathrm{COCH}_{2}\right)$, $1.98-1.84\left(\mathrm{~m}, 1 \mathrm{H}, \mathrm{COCH}_{2}\right), 1.79-1.63\left(\mathrm{~m}, 4 \mathrm{H}, \mathrm{NCH}_{2} \mathrm{CH}_{2} \mathrm{CH}_{2}\right), 1.42\left(\mathrm{~s}, 9 \mathrm{H}, \mathrm{CH}_{3}\right) .{ }^{13} \mathrm{C}$ NMR $(126 \mathrm{MHz}$, $\left.\mathrm{CDCl}_{3}\right) \delta 172.5,158.3,156.1,151.2,148.1,132.1,129.2,128.6,128.2,128.2,127.7,127.1,125.5,123.1$, $122.5,114.7,107.9,70.5,70.4,70.1,69.8,69.5,69.4,55.5,38.4,36.1,35.6,29.6,29.5,28.4$. HRMS (ESI) $\mathrm{m} / \mathrm{z}$ : Calcd for $\mathrm{C}_{34} \mathrm{H}_{47} \mathrm{~N}_{4} \mathrm{O}_{7} \mathrm{Na}(\mathrm{M}+\mathrm{Na})^{+} 645.3259$, found 645.3236 .

Compound 9: Compound 8 (116 mg, $0.19 \mathrm{mmol}$ ) was dissolved in a DCM/TFA solution (7 mL, 95:5, $\mathrm{v} / \mathrm{v}$ ) and stirred for $1.5 \mathrm{~h}$ at room temperature. The reaction was concentrated under reduced pressure and the residue was purified by column chromatography on silica gel $\left(\mathrm{CHCl}_{3} / \mathrm{MeOH}\right.$ 1:0 to 95:5, containing a $0.5 \%$ of $35 \%$ aq. $\mathrm{HN}_{4} \mathrm{OH}$ solution $\mathrm{v} / \mathrm{v} / \mathrm{v}$ ) furnishing 9 (84 $\mathrm{mg}, 86 \%$ yield) as a pale brown oil. ${ }^{1} \mathrm{H}$ NMR $\left(500 \mathrm{MHz}, \mathrm{D}_{2} \mathrm{O}^{25^{\circ} \mathrm{C}}\right) \delta 7.63(\mathrm{~d}, J=7.7 \mathrm{~Hz}, 1 \mathrm{H}, \mathrm{Ar}), 7.46-7.35(\mathrm{~m}, 6 \mathrm{H}, \mathrm{Ar}), 7.29-7.23(\mathrm{~m}$, $1 \mathrm{H}, \mathrm{Ar}), 5.02\left(\mathrm{~d}, J=14.5 \mathrm{~Hz}, 1 \mathrm{H}, \mathrm{CH}_{2 \mathrm{a}}{ }^{\mathrm{DBCO}}\right), 3.72-3.61\left(\mathrm{~m}, 11 \mathrm{H}, \mathrm{CH}_{2 b}{ }^{\mathrm{DBCO}}, \mathrm{OCH}_{2}\right), 3.52(\mathrm{t}, J=6.4 \mathrm{~Hz}, 2 \mathrm{H}$, $\left.\mathrm{OCH}_{2}\right), 3.14-2.95\left(\mathrm{~m}, 6 \mathrm{H}, \mathrm{NCH}_{2}\right), 2.32-2.16\left(\mathrm{~m}, 2 \mathrm{H}, \mathrm{CH}_{2} \mathrm{CO}\right), 1.94(\mathrm{dt}, J=13.5,6.4 \mathrm{~Hz}, 2 \mathrm{H}$, $\left.\mathrm{NCH}_{2} \mathrm{CH}_{2} \mathrm{CH}_{2}\right), 1.67\left(\mathrm{p}, J=6.6 \mathrm{~Hz}, 2 \mathrm{H}, \mathrm{NCH}_{2} \mathrm{CH}_{2} \mathrm{CH}_{2}\right) .{ }^{13} \mathrm{C}$ NMR $\left(126 \mathrm{MHz}, \mathrm{D}_{2} \mathrm{O}^{\left.25^{\circ} \mathrm{C}\right)} \delta 174.3,159.7,150.6\right.$, 147.7, 131.9, 129.1, 129.1, 128.9, 128.5, 128.1, 127.0, 125.7, 122.4, 121.6, 114.3, 107.8, 69.6, 69.5, 69.4, 69.3, 68.5, 68.3, 55.5, 37.6, 36.8, 36.3, 34.7, 29.0, 26.5. HRMS (ESI) m/z: Calcd for $\mathrm{C}_{29} \mathrm{H}_{39} \mathrm{~N}_{4} \mathrm{O}_{5}$ $(\mathrm{M}+\mathrm{H})^{+} 523.2915$, found 523.2927

Carbon Dot 3: Citric acid $(1.00 \mathrm{~g}, 5.2 \mathrm{mmol})$ was dissolved in distilled $\mathrm{H}_{2} \mathrm{O}(10 \mathrm{~mL})$ in a $250 \mathrm{~mL}$ conical flask. Ethylenediamine (EDA, $384 \mu \mathrm{l}, 5.72 \mathrm{mmol}$ ) was then added to the solution and stirred for $30 \mathrm{~min}$ to ensure homogeneity. The conical flask was then placed in a domestic microwave $300 \mathrm{~W}$ (inside a fume cupboard) and the solution was reacted for $10 \mathrm{~min}$. A viscous amber residue was obtained which was washed with a solution MeOH:Acetone 1:1 (4xtimes). The residue was then phase-separated by centrifugation and re-dissolved in $15 \mathrm{ml}$ of distilled $\mathrm{H}_{2} \mathrm{O}$. The $\mathrm{CD}$ solution was dialysed in $\mathrm{H}_{2} \mathrm{O}$ using 0.5-1 KDa MWCO Biotech Cellulose Ester membrane. The concentrate CD solution was then lyophilised to yield $1.1 \mathrm{~g}$ of $\mathrm{CD}$ as an amber powder. To remove high MW components the $100 \mathrm{mg}$ of $\mathrm{CD}$ were redissolved in $\mathrm{H}_{2} \mathrm{O}$ and filtered over Amicon Ultra spin filtration (10 KDa cut-off membrane) and liophilized furnishing $92 \mathrm{mg}$ of $\mathrm{CD}$ as an amber powder. Procedure modified from the one reported by Mondal et al. ${ }^{[16]}$ See SI for full characterization.

DBCO-CDs 2: To a stirred solution of CDs 3 (18.4 mg) in dry DMF $(1.84 \mathrm{~mL})$, HATU $(13.4 \mathrm{mg}, 0.035$ $\mathrm{mmol})$ and DIPEA ( $6.1 \mu \mathrm{L}, 0.035 \mathrm{mmol})$ were added and the solution was allowed to stir for further 15 minutes at room temperature. A solution of $9(9.2 \mathrm{mg}, 0.018 \mathrm{mmol})$ in dry DMF $(0.5 \mathrm{~mL})$ was added and the solution was stirred at room temperature for $5 \mathrm{~h} . \mathrm{H}_{2} \mathrm{O}(0.5 \mathrm{~mL})$ was then added to quench the reaction and the solution was stirred for further 10 minutes at room temperature and concentrated under reduced pressure. The residue was redissolved in aq. $0.1 \mathrm{M} \mathrm{NaOH}$ solution $(3 \mathrm{~mL})$ and stirred for $1 \mathrm{~h}$ at room temperature. The $\mathrm{pH}$ was neutralized with the addition of aq. $\mathrm{HCl} 1 \mathrm{M}$ solution $(0.15$ $\mathrm{mL})$, diluted with $\mathrm{H}_{2} \mathrm{O}(20 \mathrm{~mL})$, washed with $\mathrm{Et}_{2} \mathrm{O}(5 \times 10 \mathrm{~mL})$, and the water phase was concentrated under reduced pressure. The residue was purified via $1 \mathrm{KDa}$ cut-off dialysis membrane against water, changing the water bath 3 times over a $24 \mathrm{~h}$ period. The purified solution was then freeze-dried furnishing $2(10.2 \mathrm{mg})$ as a pale yellow solid. ${ }^{1} \mathrm{H}$ NMR $\left(500 \mathrm{MHz}, \mathrm{D}_{2} \mathrm{O}, 25^{\circ} \mathrm{C}\right)$ characteristic resonances $\delta \mathrm{ppm}=7.77-7.06$ (m, Ar), 5.14-5.04 ( $\left.\mathrm{m}, \mathrm{CH}_{2}{ }^{\mathrm{DBCO}} \mathrm{a}\right) 4.29-2.50$ (PEG linker and $\mathrm{CH}_{2}{ }^{\mathrm{DBCO}} \mathrm{b}$ ). ${ }^{1} \mathrm{H} /{ }^{13} \mathrm{C} \mathrm{NMR}$ HSQC $\left(126 \mathrm{MHz}, \mathrm{D}_{2} \mathrm{O} 25^{\circ} \mathrm{C}\right)$ characteristic resonances $\delta \mathrm{ppm}=131.6(\mathrm{Ar}), 127.1(\mathrm{Ar}), 129.1(\mathrm{Ar}), 125.8(\mathrm{Ar})$, $55.5\left(\mathrm{CH}_{2}{ }^{\mathrm{DBCO}}\right), 44.5,41.9,69.3,68.4,39.0,38.4,36.1,36.4,36.4,43.8,44.2,36.4,36.4,34.5,28.3,19.6,0.6$

\subsection{General protein/Abs conjugation procedure}

Step 1 - Azide functionalization: To a solution of protein in PBS $(100 \mu \mathrm{L}, 36.1 \mu \mathrm{M}$ for BSA or $100 \mu \mathrm{L}, 11.1$ $\mu \mathrm{M}$ Abs), different amounts of compound $1(0.1 \mathrm{mg} / \mu \mathrm{L}$ in DMSO stock solution) from 0.14 to 4.81 $\mu \mathrm{mol}$ for BSA and $0.12-2.41 \mu \mathrm{mol}$ for Abs, were added, respectively (See Table S1 and Table S2). The 
final solution was mixed in a shaker at $400 \mathrm{rpm}$ for $4 \mathrm{~h}$ at room temperature. The product was purified via spin-filtration using $30 \mathrm{KDa}$ or $50 \mathrm{KDa}$ cut-off membrane for BSA or Abs respectively, at $4000 \mathrm{~g}$ per 20 minutes. The concentrated protein solution was diluted with $100 \mu \mathrm{L}$ of PBS and concentrated again; this washing step was repeated two more times to remove unbound linker $\mathbf{1}$ and by-products of the reaction, furnishing a concentrated $\mathbf{1 0 a - f}$ or $\mathbf{1 2 a - d}$ for BSA and Abs derivatives respectively.

Step 2-CD-conjugation: The concentrated 10a-f or 12a-d solution prepared in Step 1 was diluted with $100 \mu \mathrm{L}$ of a PBS solution containing DBCO-CD $2(2 \mathrm{mg} / \mathrm{mL})$ mixed in a shaker at $400 \mathrm{rpm}$ for $16 \mathrm{~h}$ at room temperature. The product was purified via spin-filtration using $30 \mathrm{KDa}$ or $50 \mathrm{KDa}$ cut-off membrane for BSA or the Abs respectively, at $4000 \mathrm{~g}$ per 20 minutes. The concentrated protein solution was diluted with $100 \mu \mathrm{L}$ of PBS and concentrated again; this washing step was repeated three more times to remove the excess of $\mathbf{2}$ (4 washing steps were judged enough to remove the excess of 2 since no fluorescence was detected by the naked eye in the washing solution passing through the membrane under UV lamp in the last wash), furnishing a concentrated 11a-f or 13a-d solution

\subsection{Gel Electrophoresis}

SDS-PAGE on 4-12\% NuPage gels (Life Technologies) was performed for labelled and unlabelled protein/Abs samples. Loading dye was added to each sample and heated at $100^{\circ} \mathrm{C}$ for 5 minutes. SeeBlue ${ }^{\mathrm{TM}}$ (ThermoFisher Scientific) was used as a ladder. Lanes were loaded at similar protein concentrations and the gel was run with MES buffer at $180 \mathrm{~V}$ for 40 minutes. The images were acquired after staining with Pageblue (ThermoFisher Scientific/Pierce) protein staining solution.

\subsection{Western Blot analysis}

Recombinant human GFAP protein were run on $12 \%$ SDS-PAGE and transferred onto membrane via Trans-Blot Turbo Transfer System (BIO-RAD). Membrane was incubated in blocking buffer (PBS, 0.1\% Tween and $2 \%$ milk) for one hour and then incubated in primary anti-GFAP antibodies or anti-GFAPCD conjugates 13a (results and discussion) overnight in the cold room. Membranes were washed and then incubated in secondary antibodies for one hour. The membranes were washed and then visualized on a LI-COR Odyssey imaging system.

\subsection{Tissue staining protocol for GFAP immunofluorescence with Abs-CD 13a}

The tissue sections were deparaffinized and rehydrated as follows, the sections were incubated in three washes of xylene for 2 min each, followed by two washes of $100 \%$, 95\% ethanol for $10 \mathrm{~min}$ each. The sections were then washed twice in distilled $\mathrm{H}_{2} \mathrm{O}$ for 5 min each.

The tissue slides were then placed in the microwaveable vessel. Tris-EDTA antigen retrieval buffer (10 $\mathrm{mM}$ Tris base, $1 \mathrm{mM}$ EDTA solution, 0.05\% Tween 20, $\mathrm{pH} 9.0$ ) was added and placed inside a dedicated domestic microwave microwave, which was set to full power $(950 \mathrm{~W})$ until the solution came to a boil. The solution was boiled for $20 \mathrm{~min}$ from this point and left on the bench at room temp to cool for 30 mins. The slides were then washed $2 \times 5$ min with TBS plus $0.025 \%$ Triton X-100 with gentle agitation. The slides were blocked in Superblock buffer (Thermofisher, ref 37515) 30mins at room temp. The slides were drained for a few seconds (not rinsed) and wiped around the sections with tissue paper.400ul of CDs-conjugated GFAP antibody 13a (1:500) were then added per slide and incubated at $4^{\circ} \mathrm{C}$ overnight. The slides were then rinsed $3 \times 5$ min with TBS plus $0.05 \%$ Tween 20 .

Nuclear stain: The slides were equilibrated with $300 \mu \mathrm{l}$ buffer $2 \times \mathrm{SSC}(0.3 \mathrm{M} \mathrm{NaCl}, 0.03 \mathrm{M}$ sodium citrate, $\mathrm{pH}=7.0) 2 \times 3$ mins, then $150 \mathrm{ul}(500 \mathrm{nM}$ ) propidium iodide (Thermofisher, cat.no P3566) were added per slide, incubated at $37^{\circ} \mathrm{C}$ incubator for 5 mins. Afterwards, the slides were washed 6 times with buffer 2xSSC $300 \mu \mathrm{l}$. The slides were mounted using mounting medium fluromount-G and a coverslip was added. Clear nail polish was added to seal the edges around the coverslip.

\subsection{Confocal Microscopy}

Optical microscope images were acquired on a Leica DMIL Led Fluo microscope. Confocal microscope images were acquired on a Leica DMi8 inverted epifluorescence microscope using $405 \mathrm{~nm}$ and 
tuneable white light lasers and 63x (NA 1.4) objective at the Wolfson Imaging facility at the University of Bristol. The images were analysed using Fiji (ImageJ) software.

\section{Acknowledgements}

The authors thank Cancer Research UK (grant number C30758/A2979). TGM thanks EPSRC BCFN EP/L016648/1/Conacyt. This research was also funded by the European Research Council (MCG), grant number ERC-COG:648239 and by the MSCA fellowship project 843720-BioNanoProbes (JRS). The authors thank Dr. Katy Jepson and the Wolfson Bioimaging Facility for her assistance in this work.

\section{References}

[1] M. Ozawa, P. M. Brennan, K. Zienius, K. M. Kurian, W. Hollingworth, D. Weller, W. Hamilton, R. Grant, Y. Ben-Shlomo, Fam Pract 2018, 35, 551-558.

[2] Neuro-oncology Top 10 priorities http://www.jla.nihr.ac.uk/priority-settingpartnerships/neurooncology/ top-10-priorities/

[3] aC. Faulkner, A. Palmer, H. Williams, C. Wragg, H. R. Haynes, P. White, R. M. DeSouza, M. Williams, K. Hopkins, K. M. Kurian, Brit J Neurosurg 2015, 29, 23-29; bA. Harland, X. Liu, M. Ghirardello, M. C. Galan, C. M. Perks, K. M. Kurian, Front Oncol 2021, 11.

[4] J. Tichy, S. Spechtmeyer, M. Mittelbronn, E. Hattingen, J. Rieger, C. Senft, C. Foerch, J NeuroOncol 2016, 126, 361-369.

[5] K. M. Kurian, Y. Zhang, H. R. Haynes, N. A. Macaskill, M. Bradley, Clin Neuroradiol 2014, 24, 231-238.

[6] K. A. Giuliano, D. L. Taylor, Trends Biotechnol 1998, 16, 135-140.

[7] H. Zhu, J. Fan, J. Du, X. Peng, Acc Chem Res 2016, 49, 2115-2126.

[8] aS. A. Hill, D. Benito-Alifonso, D. J. Morgan, S. A. Davis, M. Berry, M. C. Galan, Nanoscale 2016, 8, 18630-18634; bS. Hill, M. C. Galan, Beilstein J Org Chem 2017, 13, 675-693; cS. A. Hill, D. Benito-Alifonso, S. A. Davis, D. J. Morgan, M. Berry, M. C. Galan, Sci Rep-Uk 2018, 8; dX. Y. Xu, R. Ray, Y. L. Gu, H. J. Ploehn, L. Gearheart, K. Raker, W. A. Scrivens, Journal of the American Chemical Society 2004, 126, 12736-12737.

[9] A. M. Derfus, W. C. W. Chan, S. N. Bhatia, Nano Letters 2004, 4, 11-18.

[10] L. M. Hu, Y. Sun, S. L. Li, X. L. Wang, K. L. Hu, L. R. Wang, X. J. Liang, Y. Wu, Carbon 2014, 67, 508-513.

[11] S. N. Baker, G. A. Baker, Angew Chem Int Edit 2010, 49, 6726-6744.

[12] aH. Ali, S. K. Bhunia, C. Dalal, N. R. Jana, Acs Appl Mater Inter 2016, 8, 9305-9313; bJ. Bartelmess, S. J. Quinn, S. Giordani, Chem Soc Rev 2015, 44, 4672-4698.

[13] aD. P. O'Neal, L. R. Hirsch, N. J. Halas, J. D. Payne, J. L. West, Cancer Lett 2004, 209, 171-176; bS. A. Hill, S. Sheikh, Q. Y. Zhang, L. S. Ballesteros, A. Herman, S. A. Davis, D. J. Morgan, M. Berry, D. Benito-Alifonsoa, M. C. Galan, Nanoscale Advances 2019, 1, 2840-2846; cM. Ghirardello, J. Ramos-Soriano, M. C. Galan, Nanomaterials-Basel 2021, 11.

[14] C. Y. Ji, Y. Q. Zhou, R. M. Leblanc, Z. L. Peng, ACS Sens. 2020, 5, 2724-2741.

[15] aS. Jampasa, N. Ngamrojanavanich, S. Rengpipat, O. Chailapakul, K. Kalcher, S. Chaiyo, Biosensors and Bioelectronics 2021, 188, 113323; bL. Zhu, X. Cui, J. Wu, Z. Wang, P. Wang, Y. Hou, M. Yang, Analytical Methods 2014, 6, 4430-4436; cC. Zhang, X. Yu, X. Shi, Y. Han, Z. Guo, Y. Liu, Food Anal. Methods 2020, 13, 1042-1049; dS. Mohammadi, A. Salimi, S. HamdGhadareh, F. Fathi, F. Soleimani, Anal Biochem 2018, 557, 18-26.

[16] S. Mondal, A. Yucknovsky, K. Akulov, N. Ghorai, T. Schwartz, H. N. Ghosh, N. Amdursky, J Am Chem Soc 2019, 141, 15413-15422.

[17] S. Qu, X. Wang, Q. Lu, X. Liu, L. Wang, Angew Chem Int Ed Engl 2012, 51, 12215-12218. 
[18] D. Benito-Alifonso, B. Richichi, V. Baldoneschi, M. Berry, M. Fragai, G. Salerno, M. C. Galan, C. Nativi, Acs Omega 2018, 3, 9822-9826.

[19] aV. Chudasama, A. Maruani, S. Caddick, Nat Chem 2016, 8, 114-119; bN. G. Welch, J. A. Scoble, B. W. Muir, P. J. Pigram, Biointerphases 2017, 12, 02D301.

[20] D. Leung, J. M. Wurst, T. Liu, R. M. Martinez, A. Datta-Mannan, Y. Feng, Antibodies (Basel) 2020, 9.

[21] N. Diamantis, U. Banerji, Brit J Cancer 2016, 114, 362-367.

[22] aP. Akkapeddi, S.-A. Azizi, A. M. Freedy, P. M. S. D. Cal, P. M. P. Gois, G. J. L. Bernardes, Chemical Science 2016, 7, 2954-2963; bP. Dennler, E. Fischer, R. Schibli, Antibodies 2015, 4, 197-224.

[23] K. M. Hamill, E. Wexselblatt, W. Tong, J. D. Esko, Y. Tor, J. Mater. Chem. B 2016, 4, 57945797.

[24] L. Signor, E. Boeri Erba, JoVE 2013, e50635.

[25] Although all azido moieties can react on the protein and be labelled with 2, this is just an approximation. Due to the molecular complexity and polydispersity of the CDs, their MW is unknown as steric hindrance might interfere with conjugation).

[26] On the other hand, ionization of the Ab-CD conjugates probe inneficient on MALDI which hamper the spectrometric validation of the CD-Ab adducts, however gel electrophorosis allowed the validation of the conjugation step. Thus the combination of both techniques is crucial for the characterization of the probes.

[27] Due to the autofluorescence of the gel, it was not possible to directly detect the presence of $A b-C D s$ using the inherent CDs fluorescence. 